\section{Influence of innovation competence on firm level competitiveness: an exploratory study}

\author{
Saurabh Srivastava
}

\author{
Shri Mata Vaishno Devi University, University in Katra, \\ Jammu and Kashmir, India, and \\ Abid Sultan and Nasreen Chashti \\ Department of Commerce, Islamia College of Science and Commerce Srinagar, \\ Kashmir, India
}

Influence of innovation competence

\begin{abstract}
Purpose - The dynamics of the competitive performance of the small medium firms is an evolving field of research in the developing countries like India. The influence of the innovation on the competitive performance of the firms is still an evolving area in India. This paper aims to explore the influence of the innovation on the competitive performance. The study is based upon the agro-food processing industry of the Jammu and Kashmir state of India.

Design/methodology/approach - The paper is based upon the exploratory design. It uses quantitative as well as qualitative method for the firm level analysis of competitiveness. The aggregate index method has been used to construct the innovation competence and total competitive performance index. The regression analysis is used for describing the model based upon the primary data.

Findings - The results of the study provide for a significant relationship between the innovation competence and firm level competitiveness. It describes the position of the agro-food processing firms under study with respect to the innovation competence index score and total competitiveness performance index.

Research limitations/implications - The paper provides for the managerial implications of strategically incubating the innovation-based competence for the firms in specific geographical areas. The policy implications in terms of developing specific clusters and incubators for incremental and radical innovations can be derived, in regional economies.

Originality/value - The paper discusses the issue of interaction of innovation competence and firm level competitiveness of the agro-food processing industry, which is dynamic, specifically in the developing states. The paper discussed unique methodology of using aggregate index method for defining the innovation competence and competitiveness for the firms where the consistency of data is a major issue for such a complex phenomenon.
\end{abstract}

Keywords Competitiveness, Innovation, Firm level competitiveness, Competitive performance

Paper type Research paper

(C) Saurabh Srivastava, Abid Sultan and Nasreen Chashti. Published in the Asia Pacific Journal of Innovation and Entrepreneurship. Published by Emerald Publishing Limited. This article is published under the Creative Commons Attribution (CC BY 4.0) licence. Anyone may reproduce, distribute, translate and create derivative works of this article (for both commercial and non-commercial purposes), subject to full attribution to the original publication and authors. The full terms of this licence may be seen at: http:// creativecommons.org/licences/by/4.0/legalcode

The authors acknowledge the support of Indian Council of Social Science and Research for their support in funding the research for Competitiveness of Food Processing Units at Shri Mata Vaishno Devi University, Katra, J\&K. The authors would like to thank all the industry participants for generously giving their time and for sharing their information and insights so willingly. The authors would also like to acknowledge their reviewers for their invaluable advice on developing this paper.

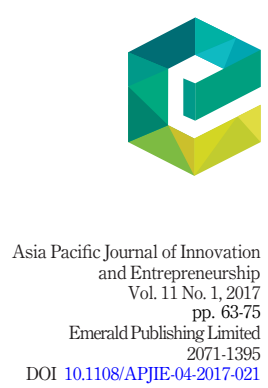

Received 12 August 2016 9 October 2016 Accepted 10 October 2016 
APJIE

11,1

64

\section{Introduction}

The competitiveness in the manufacturing sector of developing countries, like India, is based upon creating scope for the strategic interventions through the development of distinct dynamic capabilities (Teece et al., 1997). With the increase in the global competition and changing taste and preferences of the consumers, the agro-food processing firms have a challenge to respond with defining innovations in the product or process. The innovation could be radical or incremental that provides for an either competitive stability or creates a dramatic impact with disruptions in an industry and at the marketplace (Srinivasan et al., 2002; Tellis et al., 2009). The innovations and the capability to innovate with advances in technology, defining product life cycles, dynamic customer activities and re-defining international as well as local competition has become an absolute necessity for defining the competitiveness of a firm. The firms have a challenge of developing the innovation competence (which is same as competence based on innovation) for defining their competitive landscape. The challenge is more for the firms in developing countries where the scope for incubating the innovations by the firms is under intense pressure of competitive performance.

The innovation competence is more of secondary consideration in the industries where strategic decision-making is under the pressure of cost and price competitiveness. The industry sectors where the price-based competition and influence of contributions from the informal sectors are significant call for an attention of creating an approach of developing various capabilities that add to the competence. The dynamic nature of capabilities provides for an evolving resource-based competence which contributes to the competitive performance of the firms in such industry sectors. Innovation competence thus provides the dynamic capability to the firms which help them to define their competitiveness. For firms in such industry, however, the influence of innovation competence on the firm level competitiveness is an area that needs to be explored. The paper, therefore, is based upon the exploratory study conducted to understand whether innovation competence can be instrumental in defining the firm level competitiveness. The unit of analysis for the study is the agro-food processing firms in the state of Jammu and Kashmir (J\&K) in India. The study is significant in terms of creating an argument to consider the incubation and development of innovation competence in strategic decision-making. This would be instrumental in providing competitiveness to the firms that are in a fragmented industrial sector, i.e. agrofood processing industry. The industry has high influence of an unorganised sector and price-based competitive pressures. Also, the changing social and economic fabric of the Indian society is pushing the demand for the processed foods. The Indian agro-food processing industry is highly fragmented and heterogeneous.

The paper is divided in four different sections:

(1) the first part discusses the status of agro-food processing industry in India;

(2) the second part is the review of literature;

(3) the third part discusses the research methodology; and

(4) the last part discusses the findings of the research, i.e. how innovation based competence has an influence on the competitive performance of the agro-food processing firms in the state of $\mathrm{J} \& \mathrm{~K}$ in India.

The structure of agro-food-based processing industry in India

Indian domestic food market is expected to grow by 40 per cent and will have market size of US\$344bn by 2025 (Singh et al., 2012). The Indian food processing sector offers significant 
potential for the value addition which can lead to the income and employment generation as well (Ali et al., 2009). The share of Indian food processing industry in Indian manufacturing in terms of an income and profit is 5.86 and 11.95 per cent, respectively (Annual Survey of Industry, 2012/2013). However, in the Indian food processing industry, only 2 per cent of India's total agricultural and food produce is processed. It accounts for less than 1.5 per cent of international food trade. Ministry of Food Processing in India, in its Vision document 2015, has estimated the processing level of perishable products to increase from 6 to 20 per cent, value addition to increase from 20 to 35 per cent and India's share in global food trade to increase from 1.5 to 3 per cent. The performance of the agro-food processing in Indian food processing industry is summarized in Table I.

The agro-processing industry is still in an infancy stage in a promising and growing industrial sector of India. However, the agro-food processing industry in India is facing certain challenges such as road connectivity, electricity, transport, cold storage, capital, warehouses and professional management (Ali et al., 2009; Majumdar, 2012). India can take advantage of this promising industry by recognizing and developing the states that are rich in natural endowments as well as have advantages in terms of climate and soil. States like $\mathrm{J} \& \mathrm{~K}$, which is the highest temperate fruit producing state of India, with its rich agriculture and horticulture produces, offers immense economic opportunities to the agro-food processing.

With more than 70 per cent of the population dependent upon the agriculture and horticulture, the state of J\&K offers scope for the agro-food processing and can establish niche markets for its products at regional, national and international level, based upon the geo-climatic advantages of its produce (Table II).

The contemporary geo-political environment is propelling the growth of entrepreneurial activities in the state of J\&K, but still there is a significant scope for the growth and development. The agro-food processing units of the State are in an emergent need of a

\begin{tabular}{lccc}
\hline Parameters & $\begin{array}{c}\text { Food processing } \\
\text { industry (FPI) }\end{array}$ & $\begin{array}{c}\text { Agro-food } \\
\text { processing (AFP) }\end{array}$ & $\begin{array}{r}\text { Percentage share of AFP in food } \\
\text { processing industry }\end{array}$ \\
\hline Fixed capital $^{\mathrm{a}}$ & 35,095 & 31,925 & 90.97 \\
Gross value added $^{\mathrm{a}}$ & $13,398,580$ & $11,643,564$ & 86.9 \\
Income $^{\mathrm{a}}$ & $6,634,905$ & $5,457,234$ & 82.25 \\
Profit $^{\mathrm{a}}$ & $4,212,637$ & $3,333,353$ & 79.13 \\
Employment (no.) $_{\text {Fixed capital }}^{\mathrm{a}}$ & $1,990,478$ & $1,580,092$ & 79.38 \\
& $1,547,183$ & $1,314,442$ & 84.96
\end{tabular}

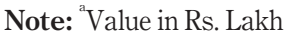

Source: ASI data for year 2012-2013

\section{Influence of innovation competence}

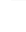


APJIE 11,1

strategic reinforcement for their survival and growth. There is a requirement to create, build and sustain competitiveness of the agro-food processing firms in the State. Manufacturing units of the agro-food processing sector provide for the potential in providing for the diverse requirements of the consumers and generation of value-based employment in the state as well as at the national level. The firms of J\&K are in the process of defining their dynamic capabilities and competitiveness. The challenges of innovation-based competence for the agro-food processing firms are the highly heterogeneous industry structure and an increasing competition with international and national players redefining the competitive landscape in the food processing industry. The innovation competence and firm level competitiveness are required to be understood in reference with the available literature.

\section{Review of literature}

Despite of having a large availability of rich resource base, the concept of competitiveness is still without any standard definition, determinants and methods of measurement. This is mainly due to the lack of consensus among the academicians, economists, practitioners and researchers about the definition of the competitiveness and its measurement method (Chaudhuri and Ray, 1997; Siggel, 2006). Competitiveness measurement is still a developing area of research. Studies often adopt their own definition and choose a specific measurement method or composite scale, depending upon the objectives of the study (Latruffe, 2010). The review of literature reveals three levels of competitiveness - nation, industry and firm level. Lately, firm level competitiveness has been regarded as an important base for building the industry and nation level competitiveness (Porter, 1990; Chaudhuri and Ray, 1997; Ambastha and Momaya, 2004). Firm level competitiveness depends upon the competencies of the firm, and these competencies are internal to the firm (Ambastha and Momaya, 2004; Porter, 1990; Nelson, 1992).

The review of literature available in the field of strategic management, strategy and economics, based upon the relevance and high citations, provides a range of variables and resources that are internal to the firm and have potential for contributing toward building, sustaining and maintaining competitiveness at the firm level. These variables include both tangible as well as intangible variables like firms' strategies, structures, competencies and capabilities to innovate, the ability to market, supporting marketing and distribution systems, technology, productivity, human resources infrastructure, operations management, innovation, supply chain management, quality systems, etc. (Prahalad and Hamel, 1990; Nelson, 1992; Ambastha and Momaya, 2004 and Chaudhuri and Ray, 1997). Among the various variables, innovation has become a compelling necessity for the firm level competitiveness, especially in the agro-food processing industry.

The importance of the innovation competence in the economic rent generation was first highlighted by the Schumpeter during 1940s followed by Solow (1957). Innovation refers to the changes in the processes and products (Priede, 2013), with inputs like financial resources, commitment, R\&D, etc., and output in terms of new products, number of patents, new manufacturing processes, etc. (Murimbika and Urban, 2014). Innovation is the way for the firms to respond to the market changes, technology changes, customer changes and competition (Dougherty, 1992). Innovation, incremental as well as radical, is one of the major reasons for the success of firms in present competitive arena. It is an instrumental in creating a firm's responsiveness toward dynamic business environment. The responsiveness can in the form of finding innovative ways to the routine operations of the 
manufacturing. As pointed by Dougherty and Hardy (1996), competitive firms link innovations to the organization in three manners:

(1) make innovation a part of organization strategy;

(2) second collaboration with structures and processes to face challenges creatively; and

(3) last ensuring the availability of the resources.

De Jong and Marsili (2006) advocated that the innovation is not a responsibility of a team or department but a job of everyone in the firm and is reflected by the management planning, attitude and external orientation. The review of literature supports that the firm's innovative behavior provides for growth, competitive advantage and competitiveness in the long-term perspective (Dougherty and Hardy, 1996; Grinyer et al., 1988; Philip and Wen, 1998).

The definition of competitiveness has been varying over the years on the industry and market basis. Along with the definition, there is not a single measure for the competitiveness measurement. Competitiveness is often defined as the output determinant business performance of the firms. The literature of operation strategy and competitiveness suggest a composite measure for evaluating the firm's competitive performance. This is in view of the fact that a single measure fails to evaluate all the dimensions of the performance (Buckley et al., 1988). The literature provides for four factors for measuring the competitive performance of the firms that are cost, quality, flexibility and dependability (Kumar et al., 1999; Shahnawaz, 2015; Hung et al., 2015; Prester, 2013). Cleveland et al. (1989) held inclusion of the financial parameter and marketing parameter important for determining the competitive performance of the firms. Based upon the various parameters, an aggregate measure for the competitive performance over these parameters could be developed for defining the competitiveness at the firm level. There are literature describing innovation-based competence as well as competitiveness with reference to the definition, resource base, but the interaction between both innovation and the competitiveness for the manufacturing units in the developing areas required further exploration. Hence, the present research paper explores the innovation competence with respect to competitiveness among agro-food processing industries in developing region like J\&K in India.

\section{Research methodology}

Based upon the gap determined in the literature the objective of the paper was to examine the influence of innovation competence on the total competitive performance of the agrofood processing firms and evaluate the level of innovation competence among the existing agro-food processing units of the J\&K state in India. To understand the phenomena of influence and unexplored status of these manufacturing firms in terms of their innovation capabilities, an exploratory research design has been adopted. A total of 75 agro-food-based manufacturing units were surveyed, of which data from 61 firms was found to be accurate for the data analysis. Data have been collected through a well-structured questionnaire based upon the five-point Likert scale.

To have a uniform standard for the innovation competence, a questionnaire was prepared to record the innovations of the firms based upon the various parameters such as new products introduced during the past five years, innovations introduced in human resource and team management, facilities in the firm for quality enhancement of existing products and facility in the firm for identification of the new manufacturing process (Table III). Cronbach's coefficient alpha of these statements was found to be 0.749 and hence validates the questionnaire. The responses obtained were aggregated to get a composite score which was defined as the innovation competence index (ICI). An index in this study

Influence of innovation competence 
APJIE 11,1

68

represents a single composite measure by aggregating different variables by taking averages or summation (Fischer and Schornberg, 2007; Momaya, 1998).

Keeping in veiw the review of literature regarding competitive performance, six variables have been used to define the total competitive performance of the firms, i.e sales performance, profit after tax performance, cost, quality, flexibility and dependability. Based upon the literature review cost, quality, flexibility and dependability variables were defined through the statements for each and every unit. The detail of the items and their desrciptive mean values are tabulated in Table IV. The data pertaining to the profit after tax (PAT) and sales was collected in absolute values and was tranformed into the likert scale to form PAT index and sales index. The competitiveness is not based upon a single factor. The role of one individual factor of business performance cannot be a basis for the pursuit for business goals. Hence, to have a broader measure of business performance for defining the competitiveness, factors have been aggregated to formulate single composite index, called as total competitive performance index (TCPI) (Cleveland et al., 1989). This index has been used as a proxy for the firm level competitiveness. To infer the influence of innovation competence on the firm level competitiveness of the selected units, a hypothesis is formulated i.e.:

HO. Innovation competence does not influence total competitive performance as a proxy for firm level competitiveness.

H1. Innovation competence influence total competitive performance as a proxy for firm level competitiveness.

The competitve performance index, i.e. the proxy for firm level competitiveness, has been regressed with the ICI to know the infleunce of innovation competence on the TCPI, i.e. firm level competitiveness (Cleveland et al., 1989). The TCPI, i.e. firm level competitiveness, is taken as dependent variable over the innovation competence as an independent variable. The validity of the model is found to be statistically significant at 5 per cent level of significance with $F$ value of 26.72 .

Further, to explore the status of the firms under the research with reference of the TCPI and ICI, the firms are arranged in the four categories i.e. low, low medium, medium high and high (Avella et al., 2001). The cross-table description explains the status of firms under survey and their respective indexes.

\section{Discussion}

The state of J\&K derives heavily out of its agriculture and horticulture produce as discussed earlier. With high geo-political disturbances and less developed industrial sector, the scope

Table III.

Descriptive statistics of statements used for innovation index

\begin{tabular}{|c|c|c|c|c|c|}
\hline Statements of innovation competence index & $N$ & Minimum & Maximum & Mean & SD \\
\hline \multirow{5}{*}{$\begin{array}{l}\text { New products introduced on an average period } \\
\text { of past five years } \\
\text { Innovation(s) introduced in human resource/team } \\
\text { management on an average period of past five years } \\
\text { Facility in the firm for quality enhancement of existing } \\
\text { products } \\
\text { Facility in the firm for identification of the new manufacturing } \\
\text { process }\end{array}$} & 61 & 0.00 & 0.48 & 0.1239 & 0.15832 \\
\hline & & & & & 0.10 \\
\hline & 61 & 0.00 & 0.48 & 0.0325 & 0.10 \\
\hline & 61 & 0.00 & 0.60 & 0.0738 & 0.14131 \\
\hline & 61 & 0.00 & 0.60 & 0.0246 & 0.09942 \\
\hline 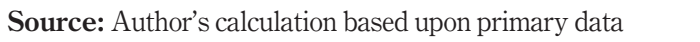 & & & & & \\
\hline
\end{tabular}




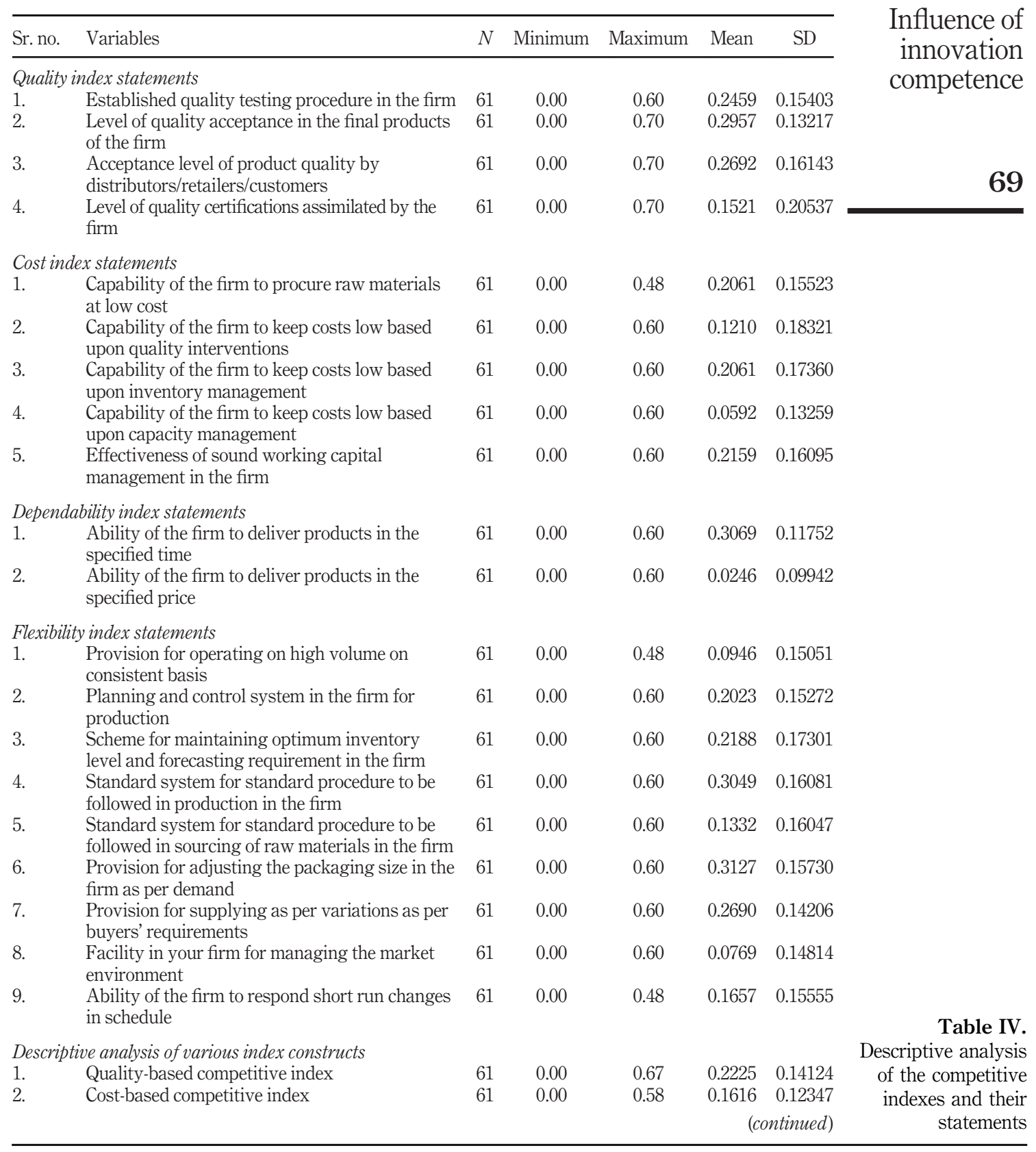


APJIE 11,1

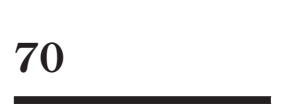

\begin{tabular}{llccccc} 
Sr. no. & Variables & $N$ & Minimum & Maximum & Mean & SD \\
\hline 3. & Flexibility-based competitive index & 61 & 0.00 & 0.57 & 0.1974 & 0.10664 \\
4. & Dependability-based competitive index & 61 & 0.00 & 0.60 & 0.1990 & 0.09943 \\
5. & PAT-based competitive index & 61 & 0.00 & 0.70 & 0.4010 & 0.26416 \\
6. & Sales-based competitive index & 61 & 0.00 & 0.70 & 0.4092 & 0.25271 \\
7. & TCPI & 61 & 0.22 & 3.82 & 1.5892 & 0.73813 \\
8. & ICI & 61 & 0.00 & 0.50 & 0.0651 & 0.09726
\end{tabular}

Table IV.

Source: Author's calculation based upon primary data

for development streams out of the immense pecuniary prospects in the agro-food processing and allied activities. The State holds distinction in the domestic and international markets for its various produce such as saffron, apple, cherry, walnut, etc. The State needs to leverage the opportunity through building upon the innovative competence of the manufacturing firms. Over the survey, it is found that the incremental as well as radical innovation in terms of new processes and new technology, respectively, has been absolutely negligible for the firms in J\&K. The firms have been comparatively rated low in terms of introducing new products; yet, they are innovating in terms of new packaging, innovative products and defining new market segments, i.e. more of an incremental innovation. The ICI is found to be uniformly low across the sample firms. More than 50 per cent of the firms under the survey are in the range of low ICI. There are 13 firms which have high ICI; yet, the score of ICI is below one that indicates very low aggregate score of the innovation indices (Table V). The innovation competence is an underinvested and underestimated area of the agro-food processing firms in J\&K. Barring few, most of the firms are launching the product on the basis of either intuition or imitation of the international and national products. The innovation is being carried on the basis of rule of thumb without collection of information from low-cost available information sources like internet, magazines, publications from government agencies, etc.

Table V.

Relative positioning of surveyed firms on TCPI W.R.T. innovation competence index (ICI)

\begin{tabular}{|c|c|c|c|c|c|}
\hline \multicolumn{6}{|c|}{ TCPI (0.22 to 3.81$)$} \\
\hline & Low & Medium low & Medium high & High & Total \\
\hline \multicolumn{6}{|l|}{ ICI (0 to 0.49) } \\
\hline High & - & $\begin{array}{l}\text { Firm } 17 \text { Firm } 1 \\
\text { Firm } 37\end{array}$ & $\begin{array}{l}\text { Firm } 32 \text { Firm } 16 \\
\text { Firm } 43\end{array}$ & $\begin{array}{l}\text { Firm } 61 \text { Firm } 18 \text { Firm } 19 \\
\text { Firm } 20 \text { Firm } 31 \text { Firm } 6 \\
\text { Firm } 2\end{array}$ & 13 \\
\hline Medium high & - & - & - & - & 0 \\
\hline Medium low & $\begin{array}{l}\text { Firm } 49 \text { Firm } \\
59 \text { Firm } 23 \\
\text { Firm } 41 \text { Firm } \\
\text { 29 Firm } 54 \\
\text { Firm } 38 \text { Firm } \\
\text { 58 Firm } 60 \\
\text { Firm } 42 \text { Firm } \\
40\end{array}$ & $\begin{array}{l}\text { Firm } 11 \text { Firm } 35 \\
\text { Firm 51 Firm } 33 \\
\text { Firm 51 Firm } 50 \\
\text { Firm } 34 \text { Firm } 30 \\
\text { Firm } 46\end{array}$ & $\begin{array}{l}\text { Firm } 5 \text { Firm } 7 \\
\text { Firm } 13 \text { Firm } 15 \\
\text { Firm } 22 \text { Firm } 24 \\
\text { Firm } 25 \text { Firm } 53 \\
\text { Firm } 36 \text { Firm } 57 \\
\text { Firm } 52\end{array}$ & $\begin{array}{l}\text { Firm } 4 \text { Firm } 12 \text { Firm } 26 \\
\text { Firm } 56\end{array}$ & 34 \\
\hline Total & 12 & 15 & 19 & 15 & 61 \\
\hline
\end{tabular}


However, with reference to the competitive performance of the targeted firms, TCPI provides an insight of high variability of competitiveness among the firms under the study. The distribution is normally spread over 61 firms. The score is above 2.5 for more than 50 per cent of the firms. Hence, the average competitiveness of the firms is above average TCPI score. However, the challenge for the firms is equally poised for the similar numbers of firms are struggling with the low level of competitiveness and hence are impeding the competitiveness of overall industry within the state. Competitiveness of the targeted firms is attributed mainly out of its price and market-based competitiveness with higher mean score in PAT index and sales index.

Ironically, the cost-based competitiveness is marginally compromised, which may be attributed to the difficult terrain as well as high cost of labor and low technological investments by the firms. The capacity of the firms in terms of cost optimization is also low. The geopolitical conditions act as constrain in defining the consistent performance of the firms and hence offers low flexibility in term of yielding high volume based upon the performance on consistent basis. These firms hence have issues in terms of providing the products in a consistent price range due to the variability in the price of factors of productions including the raw material. However, the aggregate TCPI is above one and has uniform distribution across the firms. Though, the range of distribution of TCPI across the sample firms is wide considering the small size of the sample.

To understand the spread of firms with the level of innovation competence as against the performance-based competitiveness and henceforth the positions of the firms, the firms are placed over the grid (Table V). The TCPI of the firms under survey is comparatively high as against the ICI. The grid provides for the specific firms which are comparatively high in TCPI as well as ICI are only 7 of 61 , which is only 11.47 per cent of the total firms under survey, while as 18 per cent of firms are in low category in both the areas. The scope for improvement is for nine firms which can further improve their ICI and TCPI, as they lie in the category of high and medium high (Firms 8, 9, 10, 39, 45, 14, 21, 27 and 28). The four firms (Firms 4, 12, 26 and 56) are high on TCPI but have a very low ICI score. The firms can capitalize over its strength and improve upon the ICI through adequate investment in innovation capabilities.

The interaction of the ICI and TCPI is further explained with the relationship through empirical estimation of the regression analysis. The $R$ value of 0.56 describes the significant relationship between the exogenous and endogenous variable. The 0.312 value of the $R$ square describe that the independent variable, i.e. ICI explains almost 31 per cent variability in the dependable variable, i.e. TCPI. The model thus in the case of measure of competitiveness is fit to be explained as:

$$
Y=c+a X_{1}
$$

where:

$$
\begin{aligned}
Y & =\text { Competitive performance as a proxy for firm level competitiveness. } \\
X_{1} & =\text { Innovation competence. } \\
a & =\text { coefficient of innovation competence. } \\
c & =\text { constant. }
\end{aligned}
$$

Thus, the relation is explained as:

$$
T C P I=1.313+4.238 X_{1}
$$

\section{Influence of innovation competence}


APJIE 11,1

The test statistics conclude the overall goodness of fit of the model. With reference to the findings, the null hypothesis stands to be rejected in terms of the influence of innovation over the firm level competitiveness. Hence, innovation competence does influence total competitive performance as a proxy for firm level competitiveness for the firms in agro-food processing in the state of $J \& K$ in India. The innovation holds a positive relationship with competitive performance, and with one unit investment in innovation competence, the competitive performance will increase by 4.238 units and thus will result in competitiveness of the firm in long run.

During the survey, it is observed that the agro-food processing entrepreneurs are keen toward improving innovation capabilities of their firms. It was also found that the limit of the innovation capabilities has been restricted to the products only, and most of the time entrepreneurs imitate the products of the national and international firms. Most of the entrepreneurs follow hit-and-trial method in their approach as well. However, there are certain business establishments who are consistently thinking of bringing new products or entering new market segments. One such firm, i.e. M/s Sarveshwar Overseas, with its concentrated focus was able to bring scented rice in the market. Scented rice is an exotic product of Kashmir, and during the past few decades, it was becoming almost extinct. The market for scented rice is huge both at national and international level as well as at regional levels. The firm was able to leverage on this market segment with its innovation capabilities and investment in R\&D. However, not many of such examples could be found for innovations among the firms in agro-food processing units of J\&K. It may be inferred that the agro-food processing firms of the State have failed to create a niche for its products, despite having the availability of the resources. The firms have the scope of investing and channelizing resources for building and sustaining the firm level competitiveness. Majority of the surveyed agro-food processing units in J\&K are family-oriented business and have traditional approach toward their business performance. Also, some of the units are in transition from first generation to the second generation entrepreneurs. The lack of strategic orientation and competitive motivation are hampering the success and growth of these firms. Further, the underutilization of the resources and information is also adding to the obstructions. All these factors are creating a challenge in using capabilities and hence improving and building competitive performance/firm level competitiveness. The careful investment in the innovation competence shall create a case for the increasing competitive performance. In such cases of firms where it is established empirically, that the competitiveness at firm level has an influence of innovation competence, a strategic approach in building innovation capabilities through incubation of various product and process activities can be taken up, both at structural as well as facilitating agencies. The results of the paper derive an insight for the firms to manage their competence and explore their innovation capabilities to remain competitive.

\section{Conclusion}

The present study reveals a positive relationship between competitiveness of the firms and innovation competence of the firm. With the help of the agro-food processing industries in the state of J\&K, it is established that the innovation competencies do influence the firm level competitiveness. Competitiveness of the firms is based upon creating distinct competencies and requires strategic interventions. The findings of the research paper reveal the fact that the agro-food processing firms in J\&K in India, which is a potentially resourcerich state, need strategic intervention in terms of scientific, product, technological as well as process-based innovation competencies that can lead to a non-price-based competitiveness for the firms in the state. Due to its distinct geo-political status, the firms in the State need to 
create a niche for its agro-food-processed products. The niche is based upon developing nonprice competencies, which can be developed through incubating certain incremental as well as radical innovations. The paper discussed the innovation competence of the firms with their respective status as well as comparative position.

This paper has managerial and policy implications for the firms in developing states, where the challenges are multifold. The innovation capabilities in such firms can provide for the competitive leverage to a certain level. Also, the innovation competence is based upon the product innovation as well as process innovation at incremental level as well as radical level. However, the innovation competence with respect to the developing firm level competitiveness could be only one of the parameters; still, it cannot be ignored for the firms in such geo-political status. The managers and policy makers have to consistently identify the sources and means for nurturing innovation competence. The resources and the innovations need to be incubated for competitive performance of the firms. The study provides valuable cues to the policy makers in devising the appropriate polices for improving the performance of the agro-food processing industry as well as for formulating the policy initiative/schemes for building the innovation competence of the agro-processing firms. The paper also develops upon the methodology for defining the aggregate measure for competitiveness and competence and validates with the help of its results. The aggregate measure, based upon the quantified qualitative assessment, is a way out in exploring the unknown in the absence of any uniform data for multiple units of a sample. However, one cannot ignore the limitations of biasness in the data. Hence, the observations in the papers may not be generalized for all the industry sectors across the world. The aggregate measure and development of composite index has its limitations in terms of the periodicity and ethnicity of the data. Therefore, the results may be studied carefully.

The paper provides for an insight in terms of developing innovation competence and its influence on firm level competitiveness, which may be validated further in various other industry sectors. There remains a scope of future research for deliberating and defining the measure for innovation competence for respective industry sectors as well as incubating the same for defining the same for competitiveness of the industry.

\section{References}

Ali, J., Singh, S.P. and Ekanem, E. (2009), "Efficiency and productivity changes in the indian food processing industry determinants and policy implications", International Journal of Food and Agribusiness Management Review, Vol. 12 No. 1, pp. 43-66.

Ambastha, A. and Momaya, K.K. (2004), "Competitiveness of firms review of theory, frameworks \& models”, Singapore Management Review, Vol. 26 No. 1, pp. 45-61.

Avella, L., Fernandez, E. and Vazquez, C. (2001), "Analysis of manufacturing strategy as an explanatory factor of competitiveness in the large spanish industrial firm", International Journal Production Economics, Vol. 72 No. 2, pp. 139-157.

Buckley, P.J., Pass, C.L. and Prescott, K. (1988), "Measures of international competitiveness: a critical survey", Journal of Management, Vol. 4 No. 2, pp. 175-200.

Chaudhuri, S. and Ray, S. (1997), "The competitiveness conundrum: literature review and reflections", Economic and Political Weekly, Vol. 32 No. 48, pp. M83-M91.

Cleveland, G., Schroeder, R.G. and Anderson, J.C. (1989), “A theory of production competence”, Decision Sciences, Vol. 20 No. 4, pp. 655-668.

De Jong, J. and Marsili, O. (2006), "The fruit flies of innovations: a taxonomy of innovative small firms", Research Policy, Vol. 35 No. 2, pp. 213-229.

\section{Influence of innovation competence}


Dougherty, D. (1992), “A practice-centered model of organizational renewal through product innovation”, Strategic Management Journal, Vol. 13, pp. 77-92.

Dougherty, D. and Hardy, C. (1996), "Sustained product innovation in large, mature organizations: overcoming innovation-to-organization problems", Academy of Management Journal, Vol. 39 No. 5, pp. 1120-1153.

Fischer, C. and Schornberg, S. (2007), "The competitiveness situation of the EU meat processing and bevaerage manufacturing sectors", Food Economics - Acta Agriculturae Scandinavica Section C, Vol. 4 No. 3, pp. 148-158.

Grinyer, P., Mckiernan, P. and Yasai-Ardekani, M. (1988), "Market, organizational and managerial correlates of economic performance in the U.K. electrical engineering industry", Strategic Management Journal, Vol. 9 No. 4, pp. 297-318.

Hung, S.C., Hung, S.W. and Lin, M.J. (2015), "Are alliances a panacea for SMEs? the achievement of competitive priorities and firm performance", Total Quality Management \& Business Excellence, Vol. 26 Nos 1/2, pp. 1pp. 90-202.

Kumar, A., Jaideep, M., Ceasar, D. and Narayan, D. (1999), “A quality competitiveness index for benchmarking”, Benchmarking: An International Journal, Vol. 6 No. 1, pp. 12-21.

Latruffe, L. (2010), "Competitiveness, productivity and efficiency in the agriculcture and agri-food sectors", OECD food, agriculture and fisheries paper, No 30, OECD Publishing, Rennes, available at: http://dx.doi.org/10.1787/5km91nkdt6d6-en

Majumdar, K. (2012), "Foreign direct investment in Indian food processing industry", Asian Journal of Research in Business Economics and Management, Vol. 2 No. 4, pp. 113-120.

Momaya, K. (1998), "Evaluating international competitiveness at the industry level", Vikalpa, Vol. 23 No. 2, pp. 39-46.

Murimbika, M. and Urban, B. (2014), "Strategic innovation at the firm level: the impact of strategic management practices on entrepreneurial orientation", International Journal of Innovation Management, Vol. 18 No. 2, pp. 1-38.

Nelson, R. (1992), "Recent writtings on competitiveness: boxing the compass", California Management Review, Vol. 34 No. 2, pp. 127-137.

Philip, H. and Wen, D. (1998), "The competitiveness of EU insurance industries", The Service Industries Journal, Vol. 18 No. 1, pp. 39-53.

Porter, M.E. (1990), The Competitive Advantage of Nations, MacMillan, London.

Prahalad, C.K. and Hamel, G. (1990), "The core competence of the corporation”, Harvard Business Review, Vol. 74 No. 4, pp. 79-90.

Prester, J. (2013), "Competitive priorities, capabilities and practices of best performers: evidence from GMRG 4 data", Total Quality Management \& Business Excellence, Vol. 24 Nos No. 1/2, pp. 138-157.

Priede, J. (2013), “Quality competitiveness of latvia's food industry in the fish products group”, Journal of Economics, Business and Management, Vol. 1 No. 2, pp. 192-196.

Shahnawaz, A.M. (2015), "Strategic human resource management practices and competitive priorities of the manufacturing performance in Karachi”, Global Journal of Flexible Systems Management, Vol. 16 No. 1, pp. 37-61.

Siggel, E. (2006), "International competitiveness and comparative advantage: a survey and a proposal for measurement", Journal of Industry, Competition \& Trade, Vol. 6 No. 2, pp. 137-159.

Singh, S.P., Tegegne, F. and Ekenem, E. (2012), "The food processing industry in India: challenges and opportunities", Journal of Food Distribution Research, Vol. 43 No. 1, pp. 80-88.

Solow, R. (1957), "Technical change and the aggragte production function", Review of Economics and Statistics, Vol. 39, pp. 312-320.

Srinivasan, R., Lilien, G.L. and Rangaswamy, A. (2002), "Technological opportunism and radical technology adoption: an application to E-business", Journal of Marketing, Vol. 66 No. 3, pp. 47-60. 
Teece, D.J., Pisano, G. and Shuen, A. (1997), "Dynamic capabilities and strategic management", Strategic Management Journal, Vol. 18 No. 7, pp. 509-533.

Tellis, G.J., Prabhu, J.C. and Rajesh, K.C. (2009), "Radical innovation across nations: the preeminence of corporate culture”, Journal of Marketing, Vol. 73 No. 1, pp. 3-23.

Influence of innovation competence

\section{Further reading}

Digest of Statistics J\&K (2012/2013), Directorate of Economics and Statistics, Government of J\&K, available at: http://ecostatjk.nic.in/publications/publications.htm (accessed 31 August 2016).

Food Processing Sector in India (2012), available at: www.Cci.In/Pdf/Surveys_Reports/FoodProcessing-India.Pdf (accessed 1 March 2015).

\section{Corresponding author}

Abid Sultan can be contacted at: abidsultan2012@gmail.com

For instructions on how to order reprints of this article, please visit our website: 